\title{
METÁFORAS IDEACIONAIS: PROPRIEDADES DA LÍNGUA VOLTADAS PARA O DISCURSO
}

(Ideational metaphors: language properties aimed at discourse)

\author{
Rosana Muniz Soares ${ }^{1}$ \\ (Universidade de Brasília - UnB)
}

\begin{abstract}
The purpose is to analyze how the four most quoted government proposals to the Brazilian Republic Presidency were presented in the last elections. To achieve this goal, we utilize the assumptions proposed by the Systemic Functional Linguistics (Halliday, 1994; Halliday and Mathiessen, 2004, 2014; Thompson, 2004; Taverniers, 2003). The analysis of the texts suggests a high occurrence of ideational metaphors. The data revealed that these metaphors are usually presented through nominalizations, building a scale of abstraction that disassociates social events from the experiential world, thus, concealing the social actors. These metaphors are textually built so as to construe strategic meaning effects.
\end{abstract}

Keywords: Ideational Metaphors, Systemic Functional Linguistics, meaning effects.

\section{RESUMO}

O objetivo deste artigo é analisar como foram apresentadas as propostas de governo dos quatro candidatos mais cotados à Presidência da República do Brasil, nas últimas eleições. Neste estudo inicial, foram utilizados os pressupostos da Linguística Sistêmico-Funcional (Halliday, 1994; Halliday e Mathiessen, 2004, 2014; Thompson, 2004; Taverniers, 2003). A análise dos textos mostrou que há uma grande ocorrência de metáforas ideacionais. Os dados revelaram que essas metáforas se apresentam, geralmente, por meio de nominalizações, as quais constroem uma escala de abstração que desvincula as ocorrências sociais do mundo da vida e cumprem o papel de escamotear os atores das ações. Conclui-se que tais metáforas têm grande importância nas formas do (como) dizer textos, estrategicamente, para o alcance de determinados efeitos de sentido.

Palavras-chave: Metáforas Ideacionais. Linguística Sistêmico-Funcional. Efeitos de Sentido.

\section{Introdução}

Este artigo tem como escopo central discutir como são apresentadas as propostas de governo dos quatro candidatos mais cotados à Presidência da República do Brasil, nas eleições que foram realizadas em outubro de 2014. Para tanto, busca-se realizar uma análise linguístico-discursiva dos textos, pertinentes às respectivas propostas dos candidatos, balizada pelos pressupostos da Linguística Sistêmico-Funcional (LSF), com vistas a distinguir, dentro de uma das macrofunções da linguagem de base teórica hallidayna, a ocorrência de metáforas

\footnotetext{
${ }^{1}$ Doutoranda em Linguística junto ao Programa de Pós-Graduação em Linguística da UnB. Mestrado em Linguística (UFF). Pesquisadora do Núcleo de Estudos de Linguagem e Sociedade (NELiS/UNB) e integrante do Grupo de Pesquisa LSF como instrumental teórico para ADC (CNPq/UnB). Professora/Tutora à Distância no Curso de Letras EaD da Universidade de Brasília (EaD/UnB).
} 
gramaticais do sistema de transitividade, conhecidas como metáforas ideacionais, por sua elaboração.

A metáfora gramatical destaca-se, a meu ver, como uma das propriedades da linguagem voltadas para o discurso. A propósito, Halliday (1994), entende a metáfora como um dos elementos centrais na estruturação do discurso. Por outro lado, sempre de acordo com o referido autor, a metáfora ideacional tem suas raízes na gramática de uma língua. Trata-se, assim, de um recurso poderoso na dimensão das práticas discursivas. A expressão de significados ideacionais, mediante a escolha de componentes de transitividade - por meio de processos, participantes e circunstâncias - é estendida a significações relevantes (qualidades e entidades), muito além da codificação padrão, concretizada em sintagmas nominais e verbais, que formam uma oração, unidade de sentido básica dentro de um texto.

Comenta Halliday (1994, p. 341) que, em princípio, “a metáfora é geralmente descrita como uma variação no uso das palavras, isto é, uma variação na expressão do significado". No caso do estudo ora apresentado, meu interesse é trabalhar em torno de escolhas lexicais, que configuram a nominalização, uma propriedade da linguagem que costuma imprimir uma dimensão a mais ao significado, dentro de um contexto em que determinadas escolhas são utilizadas para representar mais um mundo de coisas e não de processos. Como bem observa Halliday (2001):

...a nominalização foi funcional para a evolução da ciência experimental, possibilitando o desenvolvimento de taxionomias técnicas e desvelando as relações existentes entre processo, mas não é adequada para representar a visão de mundo mais relativística que está emergindo da ciência moderna porque representa um mundo de coisas, não de processos. (HALLIDAY, 2001, p. 19)

Em poucas palavras, no caso dos dados selecionados para o presente estudo, pode-se adiantar que, de acordo com Silva (2006), determinadas construções oracionais costumam adquirir um traço semântico diferente mediante a nominalização de um dos termos, uma vez que remetem a um significado concreto, ao mesmo tempo em que apontam para uma ideia de entidade, cuja trajetória vai do concreto ao abstrato. Parece que as construções nominalizadas costumam cumprir o papel de escamotear os atores das ações e, consequentemente, a sua agência. No caso dos dados discutidos no presente trabalho, as metáforas gramaticais indiciam maneiras de apresentação de propostas, por parte dos candidatos, como recursos estrategicamente planejados para alcançar efeitos de sentido. Trata-se, a meu ver, de 
estratégias retóricas utilizadas com a finalidade de impressionar o eleitor e, provavelmente, persuadir o cidadão indeciso.

\section{Bases teóricas}

Para Halliday (1994), todo e qualquer uso que fazemos do sistema linguístico é funcional relativamente às nossas necessidades de convivência em sociedade. Ao usarmos a linguagem, fazemos uma série de escolhas dentre as possibilidades que o sistema linguístico disponibiliza. Assim, precisamos desenvolver nossa consciência sobre os significados que as palavras e suas combinações em textos geram para alcançarmos efetivamente nossos propósitos em contextos específicos.

A Linguística Sistêmico-Funcional (LSF) configura uma teoria da linguagem de base sistêmica, uma vez que enfoca a língua como uma rede de sistemas interligados, dos quais nos servimos para construir significados, ao fazer coisas no mundo, tanto físico quanto o mundo interior de nossa própria consciência. Ressalte-se que, nessa perspectiva, cada sistema é um conjunto de alternativas possíveis que podem ser semânticas, lexicogramaticais ou fonológicas/grafológicas. Por outro lado, a característica funcional da teoria é explicada pelas estruturas gramaticais em relação ao significado, ou seja, em relação às funções que a linguagem desempenha em textos. A LSF permite-nos identificar as estruturas de um discurso, que contribuem para o(s) significado(s) de um texto. Nas palavras de Webster (2009, p.7), análises com base na perspectiva sistêmico-funcional permitem mostrar "como e por que um texto significa o que significa".

Qualquer uso linguístico que configure um texto está sempre envolvido por um contexto (MALINOWSKI, 1923). O contexto em que o texto se desenvolve está encapsulado no texto, através de uma relação sistemática entre o meio social e a organização funcional da linguagem. A propósito, um dado texto está sempre inserido em dois contextos: o de situação e o de cultura, um dentro do outro. Sempre de acordo com o referido autor, uma língua é condicionada pelo contexto de cultura e pelo contexto de situação, razão pela qual cada texto se desenvolve em algum contexto de uso.

O contexto de cultura, além de se vincular à noção de propósito social, relaciona-se ao ambiente sociocultural mais amplo, o que inclui ideologias, convenções sociais e instituições. Pode-se ponderar que grupos de pessoas que usam a linguagem para propósitos semelhantes desenvolvem, através do tempo, tipos comuns de textos escritos e falados, ou seja, gêneros que alcançam objetivos comuns. Nessa perspectiva, gêneros são dinâmicos, 
porque podem mudar através do tempo à medida que os propósitos que estabeleceram alcançar venham a mudar. Eles estão, por isso, intrinsecamente relacionados à cultura em que foram criados (HALLIDAY, 1989). O contexto de situação é o ambiente imediato no qual o texto está de fato funcionando. Por causa dessa relação íntima entre texto e contexto, os leitores podem prever o que está por vir no texto (HALLIDAY, 1989). Halliday e Matthiessen $(2004 ; 2014)$ esclarecem que a chave para a interpretação funcional da estrutura gramatical é a multifuncionalidade: os componentes linguísticos de uma mesma oração podem ser interpretados sobre diferentes enfoques ${ }^{2}$.

Os significados experienciais relacionam-se com o que se faz no mundo. A parte da gramática na qual e por meio da qual as pessoas codificam os significados da experiência chama-se sistema de transitividade. Na LSF, a transitividade é um sistema de descrição de toda a oração, que se compõe de: processos, participantes e circunstâncias. Trata-se dos componentes da transitividade como categorias semânticas, o que nos permite explicar como fenômenos de nossa experiência do mundo são construídos em termos de estrutura linguística.

Os processos constituem o elemento central da transitividade, uma vez que nos permite desvelar a gramática da experiência, seja no nosso mundo exterior ou no mundo interior das relações abstratas. Um processo é representado por um verbo propriamente, ou por um grupo verbal. São os processos que definem os participantes, os quais, por sua vez, configuram as entidades envolvidas, representadas por grupos nominais - pessoas ou coisas, seres animados ou inanimados - que levam à ocorrência do processo ou são afetadas por ele. O componente circunstancial, sempre representado por grupos adverbiais ou preposicionais, pode indiciar o modo, o tempo, o lugar, a causa, bem como o âmbito em que o processo desdobra.

\section{A caminho da compreensão da metáfora}

A metáfora, de maneira tradicional associada aos tropos de linguagem, é caracterizada por Lakoff e Johnson (1985: 47-48) como "compreender e experienciar uma coisa em termos de outra". Esses estudiosos sugerem que as metáforas penetram em todos os tipos de linguagem e fazem parte do discurso cotidiano, uma vez que nossa linguagem envolve um grande sistema conceitual metafórico, responsável por nosso pensamento e nossas

\footnotetext{
2 Os princípios teóricos da LSF estão esboçados em Halliday (1978, 1985, 1994), Halliday e Mathiessen (2004, 2014), Halliday e Hasan (1989), Eggins (2004), Martin e Rose (2003), Thompson (2004), além de vários estudiosos que consideram a importância do ambiente situacional e cultural para a língua em uso.
} 
ações. Nos termos de Thompson (2004:165), a metáfora pode ser caracterizada como "a expressão de um significado por meio de uma forma léxicogramatical que se desenvolve para expressar um tipo diferente de significado". Cabe, aqui, registrar o pensamento de Fairclough (2001, p. 241), para quem “as metáforas estruturam o modo com pensamos e o modo como agimos, e nossos sistemas de conhecimento e crença, de uma forma penetrante e fundamental".

Ao propor uma distinção entre a perspectiva tradicional e a perspectiva de uma teoria da linguagem de base sistêmico-funcional, Halliday (1994, p 340-63) dedica um capítulo a modos de expressão metafórica. Pondera o autor, que se deve olhar a metáfora não 'de baixo', como variação de significado de uma dada expressão, mas 'de cima', como variação na expressão de um dado significado. Nessa perspectiva, pode-se enfocar uma variante menos metafórica como 'congruente', como sintetizado na Figura 1 apresentada a seguir.

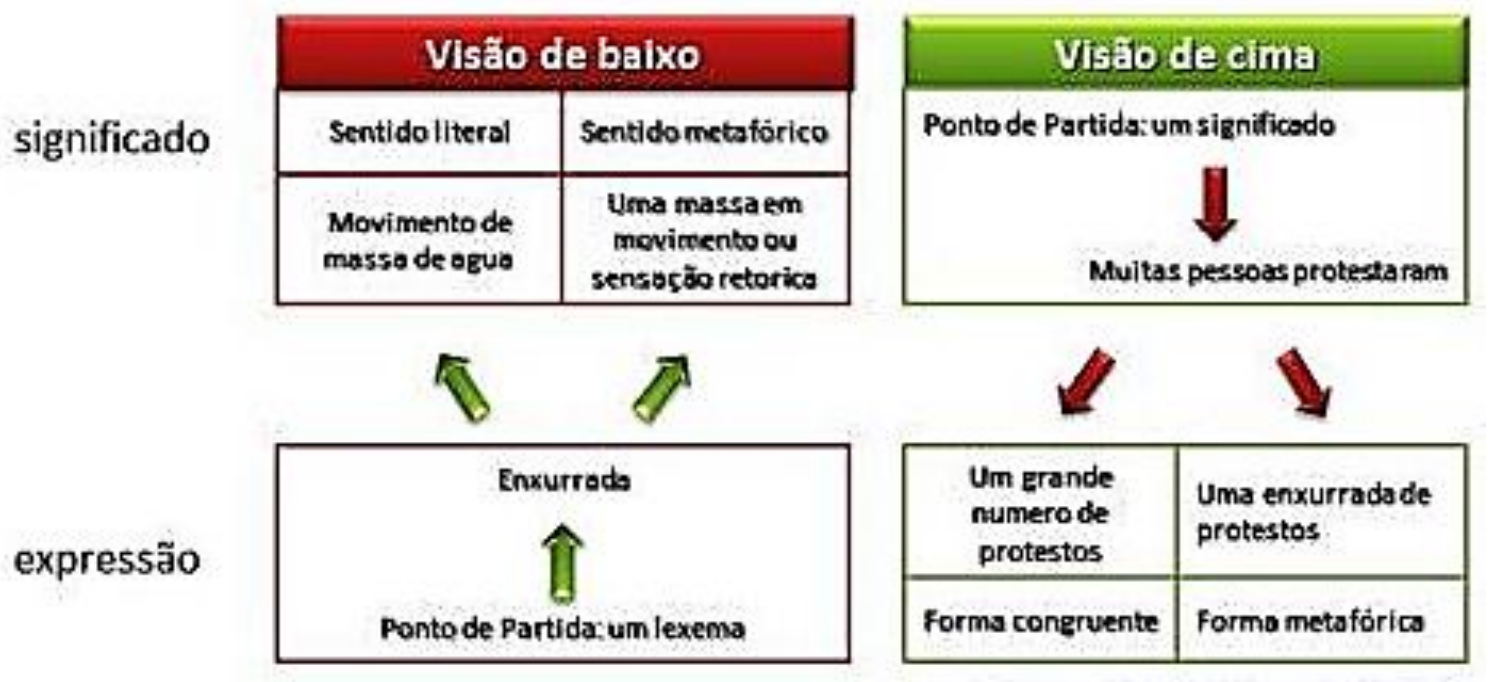

Figura 1: Metáfora gramatical

Fonte: Adaptada de Taverniers (2003)

Assim, numa dada configuração semântica haverá alguma realização na lexicogramática em que uma dada expressão será considerada congruente, por exemplo, em: “movimento de água de massa”, em oposição à ocorrência incongruente ou metafórica de “uma massa em movimento”. Essa transferência também pode ser percebida em enxurrada; muitas pessoas protestaram; um grande número de protestos, o que resulta metaforicamente em "uma enxurrada de protestos".

Não se trata de sugerir que a realização congruente seja melhor, que seja mais frequente, ou mesmo, que funcione como norma, comenta Halliday (1994), pois há vários 
exemplos em que a representação metafórica se tornou norma, o que é de fato um processo natural na mudança linguística. Nem se está sugerindo que, no conjunto de variantes, elas sejam totalmente sinônimas, pois a seleção da metáfora é por si só uma escolha significativa, já que a metáfora selecionada envolverá outros traços semânticos, que estarão sistematicamente relacionadas em significado.

Em poucas palavras, uma forma congruente é a realização gramatical prevista para a construção da oração; é a tipicidade linguística da oração, o que envolve três componentes: participante, processo e circunstância. Já uma forma incongruente é a realização gramatical não prevista, uma vez que a ocorrência de mudança na estrutura gramatical da oração costuma acarretar uma perda de informação acerca dos participantes, bem como de circunstâncias. O uso de formas congruentes ou incongruentes no discurso envolve diferentes configurações gramaticais, como o acréscimo de um sintagma preposicional, ou escolha de uma forma nominal, ao invés de um processo verbal. Por isso, uma forma incongruente também pode ser caracterizada como forma metafórica.

A transformação gramatical é o alicerce do conceito de metáfora gramatical. Há dois tipos principais de metáfora gramatical na oração: metáforas de transitividade e metáforas de modo ou, em termos do modelo sistêmico de funções semânticas, metáforas ideacionais e metáforas interpessoais, respectivamente. A propósito, com base em Halliday (1978, p. 146), vale ressaltar que a metáfora ideacional não faz parte do repertório infantil. Isso, porque se trata de um recurso de alta complexidade, que se encontra acima das funções do sistema linguístico instrumental e regulatório que emerge da criança. Pode-se ponderar que casos de linguagem metafórica, passíveis de ser encontrados na fala de crianças menores, ocorrem por meio de rimas e canções infantis tradicionais, mas tão somente associados à natureza instrumental desse sistema linguístico primeiro.

Nessa perspectiva, pode-se afirmar que os modos metafóricos de expressão são característicos do discurso do adulto. Há uma grande variação entre os diferentes registros no grau e no tipo de metáfora, mas dificilmente haverá discurso em que não ocorram metáforas. Em contrapartida, qualquer texto com um pouco mais de elaboração semântica apresenta, certamente, algum elemento metafórico que deve ser levado em consideração.

A fala apresenta padrões de uso da metáfora diferentes daqueles utilizados na escrita, porque, ao que parece, a oralidade e a cultura escrita têm diferentes modos de construir significados complexos. Isso talvez seja o fator mais determinante do uso da metáfora na gramática de um texto, de acordo com Halliday (1994). Em geral, a língua escrita se torna mais complexa por ser lexicalmente densa: ela encapsula grande número de itens lexicais em 162 
cada oração; enquanto a língua falada se estrutura com base no encadeamento de orações complexas, recorrendo à parataxe e à hipotaxe ${ }^{3}$. Desse modo, a versão escrita, de acordo com o renomado linguista britânico, é mais complexa em termos de densidade lexical, enquanto que a versão falada é mais complexa em termos de complexidade gramatical. Os itens lexicais, na versão escrita têm, assim, menos orações para acomodá-las. Não obstante, o grupo nominal constitui o recurso primário usado pela gramática para encapsular itens lexicais em alta densidade.

Quadro 1: Tipos de complexidade

Na oralidade:

As casas foram construídas com pedra e apresentavam vários arcos.

( 2 orações)

Na escrita:

Ótimas casas de pedra com numerosos arcos

(Grupo Nominal denso)

Fonte: Halliday (1994)

Assim, conforme Halliday (1994), na língua falada, o conteúdo ideacional se desenrola frouxamente, mas através de padrões oracionais que se podem tornar altamente complexos em processos de elaboração dinâmicos. Já na escrita, os padrões oracionais são em geral mais simples; mas o conteúdo ideacional é densamente encapsulado em construções nominais: aqui a complexidade é mais estática - talvez cristalina. Essas são - deve-se deixar claro - tendências gerais; nem todos os exemplos se conformam a esses padrões. Mas são características essenciais das versões escrita e oral. Pode-se afirmar que é a complexidade do tipo escrito que envolve a metáfora ideacional.

A metáfora ideacional é realizada em padrões que já existem no modo congruente de realização, mas expande esses padrões de forma significativa. Por meio desse tipo de construção, os processos e as propriedades veiculados respectivamente por ação verbal e por adjetivos são expressos metaforicamente por nomes. Nessa perspectiva, em lugar de funcionarem dentro da oração como processo ou como atributo, funcionam como coisa (HALLIDAY, 1994).

Por um lado, o refraseamento é possível porque há aspectos semânticos como causa que se manifestam repetidamente em diferentes ambientes da gramática. Por outro lado, ao

\footnotetext{
${ }^{3}$ Parataxe e hipotaxe equivalem à coordenação e à subordinação, respectivamente.
} 
invés de uma simples relação lexicogramatical, a referência metafórica constitui a resultante de uma relação semântica, em que o sentido é o captado. Nas palavras de Halliday e Matthiessen:

O processo da metáfora envolve a reconstrução dos padrões de realização na linguagem - especialmente na interface entre a gramática e a semântica. Um significado que originalmente foi construído por um tipo de fraseado passa a ser construído por outro. (HALLIDAY \& MATTHIESSEN, 2004, p. 117)

Como desdobramento da citação anterior, pode-se esclarecer que as combinações metafóricas - sequências de categorias interpretadas como valores, valores considerados como elementos, e assim por diante - abrem novo potencial de significado. A tendência geral para a metáfora ideacional é o "rebaixamento" do domínio da realização gramatical de uma sequência semântica, figura ou elemento - desde oração que liga oração, de oração a grupo/frase, e até mesmo de grupo/frase à palavra.

Sugere Moss e colaboradores (2013), cinco tipos de metáforas gramaticais que se destacam: nominalização, verbos causais, presente histórico, participantes inanimados, orações não ergativas. Explicam esses autores que a nominalização ${ }^{4}$ é um tipo de metáfora gramatical que se refere a um processo ou qualidade mediante um substantivo, em vez da realização congruente, que seria, no caso do processo, um verbo; e da qualidade, um adjetivo. A título de ilustração, em vez de uma escolha recair em uma forma verbal, tal como "transformar", a preferência recai no substantivo "transformações", como se pode apreciar no Quadro 2 apresentado a seguir.

Quadro 2: A nominalização em destaque

"No século XVIII, a sociedade britânica experimentou uma série de transformações econômicas, sociais e culturais que apareceram em toda parte".

Fonte: Moss et al (2013)

Tão produtiva quanto a nominalização é a metáfora gramatical que ocorre mediante a utilização de verbos causais, conforme explicitam os estudos realizados por Martin (1992) e Martin e Rose (2003). Na esteira do pensamento de Halliday (1994), explicam os autores que

\footnotetext{
${ }^{4}$ Mais adiante, enfocar-se-á esse tipo de metáfora gramatical nas análises de recortes de propostas de governo dos quatro candidatos mais cotados à Presidência da República do Brasil, concorrentes nas eleições que foram realizadas em outubro de 2014.
} 
a expressão de causa e efeito, através de verbos causais, constitui uma metáfora gramatical, uma vez que a forma congruente desse tipo de relação consiste em enunciar cada um dos atos relacionados por meio de seu processo (material, mental, verbal, comportamental, existencial) correspondente e estabelecer a relação de causalidade através da utilização de uma conjunção adequada.

Um dos efeitos do uso do verbo causal é que, devido à concomitante nominalização dos dois processos envolvidos, se apresenta a relação como um ato acabado, não suscetível de dúvidas ou interpretações diversas. Essa configuração de nominalizações relacionadas por um verbo causal é típica da linguagem da ciência.

Por outro lado, espera-se que a maior parte dos processos, nos livros de história, apareça no tempo passado. No entanto, em alguns dos textos que Moss e colaboradores (2013) analisaram, foi constatado um uso frequente do tempo presente no sentido histórico. Esses autores acreditam que tal uso se constitui em um caso de metáfora gramatical pela incongruência que ocorre entre o tempo gramatical utilizado e a referência temporal do conteúdo do texto, criando assim tensão entre os estratos semânticos e lexicogramaticais, o que caracteriza a metáfora gramatical.

Outros tipos de processo que geram ambiguidades na interpretação concernem aos que exibem componentes participantes com o traço menos humano, ou com o traço de inanimado. Isso acontece, em particular, nos processos mentais e, em alguns casos, os processos comportamentais e verbais, que sugerem a presença de um participante que pressupõe o traço mais humano ou, ainda, inanimado. Quando tais processos são apresentados em textos relacionados com participantes inanimados, Moss et al (2013) consideram que se trata de uma espécie de metáfora gramatical, por causa da incongruência a partir da classe dos participantes e do tipo de processo.

Outra série de estruturas linguísticas que favorecem as metáforas ideacionais podem ser encontradas em orações não ergativas que, para Moss et al (2013), fazem parte da análise da transitividade, uma vez que se diferenciam de orações ergativas, porque enquanto estas últimas tornam explícita a agência, aquelas deixam implícita a agência. As construções não ergativas, em poucas palavras, sugerem que não há nenhum agente externo relativo ao processo. Para os referidos estudiosos, as orações não ergativas são metafóricas, sobretudo, nos casos em que nos indicam que deve haver um agente externo, cuja presença está oculta pelas escolhas lexicogramaticais do escritor, como veremos a seguir no Quadro 3. 
Quadro 3: Orações não ergativas

$\mathrm{O}$ aumento da riqueza acumula enquanto milhares de homens, mulheres e crianças trabalham sem esperança e com fome.

Fonte: Moss et al (2013)

No segmento em destaque no Quadro 3, os itens lexicais "aumento" e "acumula" encontram-se atrelados a um mesmo campo lexical do termo riqueza. $\mathrm{O}$ texto parece sugerir que o aumento da riqueza, mediante a ação "acumular" se dá por si só. No entanto, nossa gramática da experiência enquanto ser social, pertencente a um grupo cidadão, indica que, no mundo real, isso não é assim. A riqueza não tem nem vontade nem capacidade de ação. Nesse caso, então, há no mundo real um participante - ator - que não aparece no texto. A ausência do agente da ação verbal camufla as informações.

Outro tipo de metáfora gramatical é a interpessoal, que ocorre na expressão de modo e modalidade, conforme destacado no Quadro 4.

Quadro 4: Metáfora interpessoal

Provavelmente esse pudim nunca ficará pronto.

Eu não acredito que esse pudim ficará pronto.

Fonte: Halliday (1994)

Nos segmentos oracionais acima, observemos que "Eu não acredito" funciona como uma expressão de modalidade; e que "provavelmente" é um termo considerado não metafórico. Entretanto, nem sempre é possível afirmar-se exatamente o que é ou o que não é uma representação metafórica da modalidade, de acordo com Halliday (1994). Isso, porque os falantes têm infinitos modos de expressar suas opiniões.

Pode-se, aqui, ponderar que o segundo segmento oracional do Quadro 4 poderia ser substituído, sem perda de sentido, por "eи creio que”, é óbvio que ... ; todos admitem que...; seria tolice negar que... ; a conclusão nem poderia ser evitada que... ; nenhuma pessoa sã iria fingir que...; o senso comum determina que... ; todas as autoridades no assunto concordariam que...; você não duvidaria que... entre outras construções alternativas dentro do português brasileiro.

A metáfora ideacional - objeto de estudo do presente trabalho - tem como sentido a reorganização do mundo natural/real e a nominalização como transformação de eventos do mundo real em unidades textuais por meio de processos de referências. Lembra Halliday 166 
(1994), a nominalização é um recurso poderoso na criação dessa metáfora, uma vez que se trata de uma propriedade da linguagem que, dentro de uma escala de abstração, permite ao falante/escritor desvincular as ocorrências sociais do mundo da vida.

É chegada a hora de enfocarmos a análise das nominalizações nos dados selecionados. Trata-se de um recorte de propostas de governo dos quatro candidatos mais cotados à Presidência da República do Brasil, nas eleições que foram realizadas em outubro de 2014.

\section{Análise de dados: propostas de governo}

Nesta seção, apresentamos uma análise de fragmentos selecionados, retirados de propostas de governo. A análise recai em construções metafóricas, principalmente, porque, como sugere Fairclough (2001, p. 241), “algumas metáforas são tão profundamente naturalizadas no interior de uma cultura particular que as pessoas não apenas deixam de percebê-las na maior parte do tempo, como consideram extremamente difícil escapar delas no seu discurso, pensamento ou ação, mesmo quando se chama sua atenção para isso". No caso dos documentos selecionados, propostas de candidatos, pode-se conceber que os textos tenham passado pelo crivo avaliativo de assessores dos respectivos candidatos presidenciáveis. Não obstante, como sugere Halliday (1994), uma língua em uso deixa sempre alguma marca na gramática. Isso, porque a língua é condicionada pelo contexto de cultura e pelo contexto de situação (HALLIDAY, 1989). Nessa perspectiva, cada texto se desenvolve em algum contexto de uso, razão pela qual no âmbito deste trabalho, apropriamo-nos de fragmentos empíricos colhidos na exterioridade linguística - o discurso de candidatos, voltado para seus respectivos planos de governo para mergulhar na análise das construções metafóricas a partir das escolhas lexicogramaticais.

Quando falamos/escrevemos, fazemos escolhas léxico-gramaticais. Então, trabalhamos com dados empíricos da realidade, analisamos o que está acontecendo no texto, o que realmente foi falado/escrito. Assim, ao analisar propostas de governo dos quatro candidatos mais cotados à Presidência da República do Brasil, nas eleições que foram realizadas em outubro de 2014, com base nos estudos de Halliday e Mathiessen (2004), percebemos que o uso das nominalizações presentes em tais propostas não é ingênuo, como veremos a partir do Quadro 5 apresentado a seguir. 
Quadro 5: Diretrizes gerais do plano de governo de Aécio Neves

COMPROMISSO FUNDAMENTAL - Reafirma-se o compromisso básico e fundamental com a defesa das liberdades do povo brasileiro, por meio da defesa firme da liberdade de imprensa, da liberdade de opinião e de expressão, da independência dos Poderes da República, da Federação, fundamentos de nossa democracia, e que permeiam todas as políticas públicas. Esse é um compromisso firmado com cada cidadão brasileiro.

Observe-se, nesse excerto da diretriz de plano de governo do candidato, que o processo defender é substituído pela forma lexical defesa, um caso típico de nominalização que despersonaliza o agente. Parece que o proponente sabe o que isso significa, entretanto, o cidadão leitor nem sempre sabe o que realmente está sendo dito. E, assim, esse tipo de discurso metafórico tende a distinguir o especialista do não iniciado. Como consequência, o candidato se distancia do eleitor, que nem sempre é capaz de pressentir que a agência da ação permanece oculta, mediante uma nominalização. Mais que uma propriedade da língua, tratase, nesse caso, de uma manobra discursiva.

Quadro 6: Plano de Governo do Pastor Everaldo

A modernização da infraestrutura e da mobilidade urbana, com parcerias público-privadas e plena concorrência é a melhor solução para o chamado "custo Brasil" que hoje impede a competitividade de nosso empresariado no exterior, destrói nossa produtividade e reduz nossa criação de riquezas, afetando a vida de brasileiros de todas nossas classes sociais.

Quadro 7: Plano de Governo do Pastor Everaldo

O meio ambiente seguro e limpo gera bem estar devendo ser observado tanto no campo quanto nas cidades. Há uma distorção da ação estatal no setor com muita burocracia na expedição de licenças e nenhuma fiscalização posterior.

Nessas duas partes do plano de governo, do mesmo candidato mencionado anteriormente, identifica-se o mesmo tipo de nominalização. O nome modernização é empregado em substituição ao processo modernizar e também o nome distorção, em vez do uso do processo distorcer. Observamos que, quando os padrões oracionais são substituídos por nomes, alguma informação é perdida, nesse caso há o escamoteamento do sujeito oracional, o que não nos permite saber quem são os agentes dessas diretrizes do plano em questão. 
Observa-se também que as orações em destaque são não ergativas, porque deixam implícitas a sua agência, sugerem que não há nenhum agente externo relativo ao processo. $\mathrm{O}$ autor está encoberto, devido às escolhas lexicogramaticais utilizadas pelo escritor que, estrategicamente, emprega o recurso da dissimulação nesse segmento discursivo.

Quadro 8: Programa de Governo de Marina Silva

A despedida de Eduardo foi a afirmação da dignidade da Política.

Quadro 9: Programa de Governo de Marina Silva

Nenhuma mudança acontecerá, contudo, sem uma ressignificação da política e uma nova sintonia da população com as virtudes democráticas.

Nos excertos acima, que integram a apresentação de uma mesma proposta de governo, a então candidata vale-se também do recurso da nominalização, mediante a escolha do item lexical afirmação, em vez do processo afirmar, bem como do item lexical derivado ressignificação, em vez do processo ressignificar. Essas escolhas metafóricas imprimem ao discurso não só uma carga retórica, mas também permitem desvelar a distinção entre o especialista e o não iniciado. Parece que, no caso, a candidata distancia-se de sua proposta política. Resulta que, muitas vezes, não se desvela no que o texto está emanando, assim, não logra perceber que essas nominalizações projetam uma realidade estática que, como se fosse uma "pintura", pede apenas a observação de um cidadão leitor contemplativo.

Quadro 10: Programa de governo de Dilma Roussef

A competitividade produtiva será atingida por meio dos investimentos em produção e consumo de massa, investimentos em infraestrutura social e econômica, na construção de um Brasil sem Burocracia e nas áreas de Educação, Ciência, Tecnologia e Inovação, construindo uma sociedade do conhecimento.

Observe-se, já no início do excerto, que o termo competitividade produtiva, que aparece topicalizado, ocupa o lugar de participante como meta, cujo alcance se dá mediante componentes circunstanciais apresentados em forma de instrumentos: por meio dos investimentos em produção e consumo de massa, investimentos em infraestrutura social e econômica. No programa de governo da candidata, hoje, presidente empossada, a 
nominalização da forma lexical construção, utilizada no lugar do processo construir, indicia, ao que parece, uma espécie de escamoteamento dos participantes com poder agentivo, não deixando claro o sujeito da ação de construir, que aparece marcada em forma gerundiva (construindo), escolha que favorece a impessoalidade.

O excerto em análise também parece sugerir que a oração não ergativa, em especial no trecho "na construção de um Brasil sem Burocracia e nas áreas de Educação, Ciência, Tecnologia e Inovação", se dá por si só. Entretanto, nosso conhecimento nos indica que, no mundo real, isso não é assim; a construção não tem nem vontade nem capacidade de ação. Assim, nesse caso, há no mundo real um participante - ator - que não aparece no texto. A inexistência do agente da ação verbal dissimula as informações, portanto leitores não tão experientes no assunto tratado, podem não perceber a habilidade discursiva empregada pelo escritor desse programa de governo.

Observe-se que as metáforas ideacionais, presentes nas propostas acima, através das nominalizações, em que naturalmente o emprego dos processos revelaria os participantes e as eventuais circunstâncias, não são aleatórias. Ressaltamos, aqui, a importância das escolhas léxico-gramaticais dos autores dos planos de governo analisados. Resulta que cada escolha no sistema linguístico adquire seu significado em relação a outras escolhas que poderiam ter sido feitas e não o foram. Essas nominalizações escolhidas contribuem para a construção de uma dada representação de mundo e, como tal, envolvem também aspectos relacionados ao poder.

Apesar de poucos dados analisados, pode-se afirmar que a utilização dessas metáforas gramaticais configura uma estratégia para a omissão do agente e, com isso, não apresentar o responsável pelo o que é dito com quem é dito. Pode-se sugerir, ainda, que há uma falta de compromisso com a realidade e, ao mesmo tempo, uma universalização dessa veridicidade. As nominalizações presentes nos excertos analisados, oriundos de documentos concernentes a planos de governo podem, em condições favoráveis, servir como alerta para guiar nossa atenção no que concerne à formação de uma consciência cidadã, que nos beneficie frente a tentativas de desviar o nosso olhar crítico de propostas voltadas mais para o mundo das coisas, enquanto propostas veladas, que dos processos transformadores. 


\section{Considerações finais}

Buscou-se, com base nos aportes da Linguística Sistêmico-Funcional, focalizar a língua em uso. Para tanto, traçou-se um caminho analítico, cujo ponto de partida foi a interioridade da linguagem (gramática) na busca de metáforas ideacionais, enquanto propriedades da língua voltadas para o discurso, no caso, discursos embasados em propostas de natureza política. Observamos que as metáforas ideacionais constituem um recurso bastante produtivo para camuflar agentes, bem como metas. Pode-se afirmar que as construções metafóricas identificadas nas análises favorecem a tentativa de persuasão, por parte dos candidatos, para "atingir sistemas de conhecimento e crença de uma forma penetrante e fundamental", em termos de Fairclough (2001, p. 2451). Como lembra Webster (2009), trata-se da instanciação de um potencial amplo de significados que pode, simultaneamente, construir experiências e estabelecer relações sociais de modo organizado.

À guisa de conclusão, por meio da análise linguístico-discursiva, buscou-se descortinar, ainda que parcialmente, propostas de natureza política que costumam servir de base para manutenção das relações assimétricas de poder. Portanto, para que valores, crenças e relações de poder passem a ser repensados e transformados é fundamental que o leitor/ouvinte cidadão possa perceber que a utilização das metáforas gramaticais, a partir das análises apresentadas, revela tamanha importância nas maneiras de um proponente se expressar de uma forma estrategicamente planejada, para alcançar efeitos de sentido.

Recebido em: março de 2015 Aprovado em: junho de 2015 zanamunizporto@gmail.com

\section{Referências bibliográficas}

EGGINS, S. An introduction to systemic functional linguistics. London: Printer Publishers, 2004.

FAIRCLOUGH, N. Discurso e mudança social . Org. ver. técnica e prefácio de I. Magalhães. Brasília: Editora Univesidade de Brasília, 2001.

FUZER, C. \& CABRAL, S. R. S. Introdução à gramática sistêmico-funcional em língua portuguesa. Campinas: Editora Mercado de Letras, 2014. 
GUIO, E.; FERNÁNDEZ, M. D. Linguística sistémico-funcional: aplicaciones a la lengua española. Santa Fe: Universidad del Litoral, Waldhuter Editores, 2008.

HALLIDAY, M. As bases funcionais da linguagem. In: DASCAL, M. (Org.). Fundamentos metodológicos da Linguística, vol. 1 p. 125-16. (Série Linguagem, comunicação e sociedade). São Paulo: Global Universitária, 1978.

An introduction to functional grammar. London: Arnold, 1985.

An introduction to functional grammar. 2nd. ed. London: Arnold, 1994.

Language as a social semiotic: the social interpretation of language and meaning. London: Edward Arnold, 1978.

Part A. In: Halliday, M. A. K.: HASAN, R. Language, context, and text: aspects of language in a social-semiotic perspective. Oxford: Oxford University Press, 1989.

HALLIDAY, M. \& MATTHIESSEN, C. An introduction to functional grammar. London: Hodder Arnold, 2004.

. An introduction to functional grammar. $4^{\mathrm{a}}$ ed., Oxford, London: Arnold, 2014.

News ways of meaning: The challenge of applied linguistics. In: FILL, A. \& MÜHLHÄUSLER, P (orgs.), pp. 175-202, 2001.

LAKOFF, G.; JOHNSON, M. Metáforas de la vida cotiadana. Cátedra: Teorema, 1985 [1980].

MARTIN, J.; ROSE, D. Working with discourse: meaning beyond the clause. London, New York: Continnum, 2003.

MOSS et al. La metáfora gramatical en los textos escolares de Ciencias Sociales en español. In: ONOMÁZEIN Revista semestral de lingüística, filología y traducción, Chile, v. 28, p. 88 104, 2013.

SILVA, D.E.G. Metáforas sob a lupa da análise de discurso crítica. In: SILVA, D.E.G. (Org.). Língua, gramática e discurso. Goiânia: Cânone Editorial, 2006, p. 161-178.

TAVERNIERS, M. Grammatical metaphor in SFL: a historiography of the introduction and initial study of the term. In: SIMON-VANDERBERG, Anne-Marie; TAVERNIERS, Miriam; RAVELLI, Louise (eds). Grammatical metaphor. Amsterdam: John Benjamins, 2003, p.5-33.

THOMPSON, G. Introduction functional grammar. 2ed. London: Arnold, 2004.

WEBSTER, J. Introduction. In: HALLIDAY, M. A. K.; WEBSTER, J. Continnum Companion to Systemic Functional Linguistics. New York: Continnum International Publishing Group, 2009. 